\title{
A pesquisa no ensino superior: um ensaio sobre metodologia científica
}

\author{
Fernando Castro Amoras ${ }^{1}$ e Aluana Vilhena Amoras ${ }^{2}$
}

\begin{abstract}
1 Mestre em Desenvolvimento Regional e Graduado em Ciências Sociais, ambos os cursos pela Universidade Federal do Amapá. Técnico em Assuntos Educacionais da Universidade Federal do Amapá, Brasil. E-mail: fernandogentry@hotmail.com

2 Especialista em Metodologia do Ensino de Língua Francesa e das Literaturas de Expressão Francesa pela Faculdade APOENA e Graduada em Letras - Francês pela Universidade Federal do Amapá. Professora do Governo do Estado do Amapá, Brasil. E-mail: aluana.amoras@hotmail.com
\end{abstract}

RESUMO: Este artigo objetiva debater o processo de pesquisa científica alinhavada ao processo de educação no ensino superior. Desta forma, procura explanar sobre a atividade de iniciação científica que ocorre nas universidades, dentro da perspectiva constitucional do tripé acadêmico de ensino, pesquisa e extensão. Será discutida a utilidade da história da ciência como forma de apresentar os feitos científicos aos alunos. A caracterização dos tipos de conhecimentos e as categorias de pesquisa e de procedimentos científicos são outros itens apresentados, didaticamente por meio de exemplos reforçadores, para favorecer a compreensão dos conceitos envolvidos na realização dos processos de pesquisa.

Palavras-chaves: Ciência. Educação. Métodos. Universidade.

\section{Research in higher education: an essay on scientific methodology}

ABSTRACT: This article aims to discuss the process of scientific research aligned with the process of education in higher education. In this way, it tries to explain about the activity of scientific initiation that occurs in the universities, within the constitutional perspective of the academic tripod of teaching, research and extension. The usefulness of the history of science as a way of presenting scientific achievements to students will be discussed. The characterization of the types of knowledge and the categories of research and scientific procedures are other items presented, in a didactic way through reinforcing examples, in order to favor the understanding of the concepts involved in carrying out the research processes.

Keywords: Science. Education. Methods. University.

\section{INTRODUÇÃO}

As instituições de ensino superior desempenham a função de formar profissionais graduados e pós-graduados por meio da viabilização de ações integradoras, articulando o ensino, a pesquisa e a extensão, com o envolvimento do seu corpo docente, discente e técnico-administrativo. Os acadêmicos envolvem-se na pesquisa científica por meio de uma iniciação que se dá em aulas teóricas e práticas, palestras, colaboração em projetos experimentais e de pesquisa, monitorias, elaboração de trabalhos de conclusão de curso e monográficos, estudos individuais e em grupos e participação em eventos científicos (GOMES; ALVES, 2017).

Objetiva-se, por meio deste artigo, e com uma abordagem de fácil compreensão, debater sobre a ciência presente no nosso diaa-dia. A partir da afirmação de que a pesquisa científica é um aliado ao processo de ensino, principalmente nas universidades, neste artigo tratar-se-á sobre a presença do fazer ciência no meio acadêmico, debatendo inicialmente sobre a prática da iniciação científica alicerçada dentro do tripé consti- 
tucional das universidades brasileiras, de ensino-pesquisa-extensão. Em seguida, será abordada a utilização didática da história da ciência, como estratégia que facilite e atraia os jovens para a atividade de pesquisa. Os tipos de conhecimentos e de pesquisa, bem como os procedimentos científicos, serão apresentados com o auxílio de exemplos ilustrativos, para favorecer a assimilação dos conceitos que estão presentes na prática científica.

\section{INICIAÇÃO CIENTÍFICA NO ENSINO SUPE- RIOR}

Durante o período de participação na iniciação científica, desenvolvem-se capacidades mais diferenciadas nas expressões escrita e oral, e a aprendizagem de conhecimentos que marcam a vida escolar dos indivíduos. Por exemplo, os estudantes passam a ler bibliografias de forma crítica, tornando-se referencial para os outros alunos.

A iniciação científica não existe somente a partir do ensino superior, nem apenas em um tipo de atividade que é a pesquisa científica, da qual se participa sob a orientação de um professor-pesquisador. Ela está vinculada a todas as atividades acadêmicas e começa, em todas as áreas das ciências, muito antes do ensino superior. A ação educativa não se faz apenas na transmissão de conhecimentos, mas, e principalmente, na interação entre aluno-professor, de modo que o resultado seja a formação de indivíduos conscientes de seus papéis sociais, como agentes ativos de transformação da sociedade.

A iniciação científica está presente na vida das universidades, principalmente públicas, fato discorrido por Fava-de-Moraes e Fava (2000) em um artigo em que demons- tra a importância do programa de iniciação científica para o estudante do ensino superior, enfatizando o papel complementar de melhoria da sua análise crítica, maturidade intelectual, compreensão da ciência e possibilidades futuras tanto acadêmicas como profissionais. É destacada a necessidade de formação de gente capacitada nas áreas técnicas e científicas como premissa para o desenvolvimento social e econômico.

A Constituição Federal do Brasil de 1988 comunica que as universidades realizarão atividades de ensino, pesquisa e extensão (BRASIL, 1988). O ensino acontece em sala de aula, por meio das várias disciplinas que os alunos cursam, das palestras que assistem, dos cursos que frequentam e das capacitações técnico-científicas em que se envolvem.

A pesquisa dá-se por meio de práticas científicas e metodológicas, aplicadas a determinadas circunstâncias visando obter algumas conclusões e soluções para dificuldades fenomenais que possam surgir e para algumas que se requer solução. As atividades laboratoriais envolvem a pesquisa, bem como a elaboração dos trabalhos finais de conclusão de curso, tais como os monográficos individuais e coletivos.

A extensão está presente em situações em que são realizadas ações que não se referem diretamente ao ensino nem à pesquisa, como, por exemplo, as ações sociais realizadas junto da população do entorno da universidade, os eventos científicos e acadêmicos feitos, como os congressos e seminários. Também se enquadram na extensão as ações realizadas pelas instituições objetivando dotar os discentes de estruturas que favoreçam as suas respectivas permanências na instituição e a conclusão do curso, como as capacitações para cursos de 
idiomas, elaboração de trabalhos acadêmicos, os auxílios financeiros para fins didáticos, e o próprio restaurante universitário.

Durante o período universitário, os alunos estarão envolvidos em diversas situações que perpassarão necessariamente pelo tripé universitário (SOUSA SOBRINHO, 2017). A atividade de ensino será feita nas disciplinas que cursarão, a participação nas aulas, com as leituras dos materiais didáticos, dos livros, dos vídeos, e outros meios de ensino. A pesquisa dar-se-á quando direcionadas pelos professores, para a realização de alguma tarefa que envolva prática de pesquisa científica, e principalmente no fim do curso com a elaboração do trabalho de conclusão de curso. A extensão será feita nos eventos científicos que frequentarem, principalmente porque precisam cumprir a carga horária das atividades acadêmicas científicas e culturais.

Na prática, é mais fácil entender-se estas três situações quando já se está de longo prazo inserido no ambiente acadêmico. Por exemplo, um aluno neófito apresentará dificuldades para descrever o que vem a ser a extensão e a pesquisa, sendo que pelo senso comum a pesquisa é unicamente aquela realizada nos laboratórios científicos, e, por experiência própria, sabemos que não é bem assim. A realização de leituras e esquematizações de conteúdos são passos importantes e integrantes e presentes na pesquisa científica.

O tripé acadêmico do estudante universitário deve estar em constante interação, pois as experiências por que passarem se agregarão aos seus Know-hows, e assim não se as podemos descartar e nem alterá-las sobremaneira. $\mathrm{O}$ que acontece é uma complementação do que temos, que entendemos como um processo de aprimoramento social e biopsiquíco. O conhecimento se amplia, e muitas informações novas são somadas e apenas utilizamos aquelas que sejam mais necessárias às nossas necessidades imediatas.

Às vezes, tanto o objeto cognoscível torna-se capaz de fazer-se inteligível, como também o objeto intangível pode tornar-se elemento de nossa capacidade de abstração, pois esta é ilimitada. Dependendo da esfera de conhecimento que estamos nos referindo o cognoscível alia-se ao incognoscível, pois no caso religioso, a fé é um aspecto que retira as limitações sensoriais e precisamos trabalhar com o desconhecido. Isto se dá até mesmo no conhecimento científico, pois existem muitas informações que não são possíveis de tratamento científico adequado, com uma fundamentação mais rígida, porém os dados capturados não são descartados, esperando uma oportunidade de receberem a descrição acadêmicocientífica devida.

\section{USO DA HISTÓRIA DA CIÊNCIA NO ENSI- NO}

A transmissão do conhecimento deve ter sempre como objetivo a formação de cidadãos responsáveis e conscientes das decisões que nos afetam e afetam os outros. $O$ conhecimento científico é perpetuado com sua transmissão de uma geração de profissionais para outra, sendo esta transmissão feita algumas vezes por meio de manuais, em que se prioriza o que parece ser o mais importante naquele momento. Desta forma, muita coisa é deixada de lado, sem a devida consideração epistemológica. Se se repassassem aos estudantes todo um conteúdo histórico-filosófico da ciência, com certeza o tempo necessário seria curto, da- 
da a imensidão do desenvolvimento científico que há. Mas, há certa importância em se adotar tal metodologia didática, pois permitirá ao aluno ter uma ideia da conjuntura social e política que o cientista estava vivenciando para formular suas teorias. Isto permite que ao aluno saber os problemas que permeavam o imaginário científico de épocas passadas, e fazer um comparativo com a época atual, vendo como a ciência evoluiu e o conhecimento se transformou.

Certamente que há vertentes contrárias à utilização da história da ciência no ensino, pois há dificuldade em se saber qual parte da mesma deve ser salientada e qual deve ser descartada. Ainda há a dificuldade existente de qual perspectiva deve ser vista: a do historiador ou a do cientista? E não se deve esquecer para quem se está ensinando, para qual faixa etária. Assim, deve-se adotar uma história simplificada, mas com fundamentação sólida; que busque incrementar a cultura geral do aluno e ser-lhe útil com a problemática das concepções alternativas.

A utilização didática da história da ciência permite desmistificar ao aluno a crença de que as concepções de mundo outrora aceitas não são mais nem menos científicas do que as atuais. $O$ fato é somente este: que 0 pensamento científico se modifica com o tempo, e que os diferentes conjuntos de crença, teorias e concepções estruturam a história do pensamento científico. Também não se pode superdimensionar a contribuição da história junto ao ensino, pois se alimentaria algumas expectativas que não seriam devidamente respondidas, tendo em vista que todo relato histórico pressupõe uma interpretação subjetiva do fato.

Acontece, algumas vezes, de apresentarse aos estudantes uma história da ciência de má qualidade, já que uma seleção da história dos assuntos de determinado ramo do conhecimento será sempre um subconjunto de um intrincado emaranhado de eventos que possuíam dinamicidade ativa na época em que ocorreram (ALFONSOGOLDFARB, 2004). Porém, não se deve subordinar a história da ciência aos objetivos únicos do ensino, qual seja o de dar uma visão geral dos assuntos aos alunos, facilitando o aprendizado dos conceitos científicos, pois se estaria fazendo um mau uso da história, que pode propagar uma imagem distorcida e até vulgarizar muitos dos mais impressionantes avanços do conhecimento científico. Chega-se até a desfigurar o trabaIho do cientista, apresentando-o numa realidade distante da que ocorreu.

A história da ciência quando aplicada de forma adequada ao ensino permite muitas possibilidades, e devemos sempre buscar metodologias que proporcionem conforto no esclarecimento das pessoas quanto ao real uso da ciência, que não deva ser vista como bem exclusivo de uma parcela da sociedade, os cientistas.

\section{OS TIPOS DE CONHECIMENTO}

Não se pode esquecer que o ato de estudar dá-se em diversos ambientes, e o mais comum é pensar-se que só acontece em estabelecimentos de ensino regulares. No entanto, mesmo as pessoas que concluíram o ensino formal, com certeza que não deixaram em nenhum momento de estudar, pois as leituras que fazemos, todos os dias, dos diversos aspectos que se antolham à nossa volta são estruturas processuais intelectivas que caracterizam a continuidade do fluxo de aprendizado. Quando não estudamos, estamos envolvidos em outras ativi- 
dades, e estaremos sempre buscando a continuidade de nossas motivações internas, seja para o aspecto familiar, religioso, profissional etc.

O ser humano possui características que Ihe diferenciam do restante do reino animal. Falamos do raciocínio, que é a capacidade da intelecção inerente a todos os seres humanos, sendo que nos demais animais é muito reduzido, tomando o ser humano um referencial comparativo máximo. Além do mais, nos outros seres do reino animal, principalmente na classe dos mamíferos, há a presença preponderante do instinto, que é um mecanismo que faz os animais agirem por impulso, por motivação biológica, e outras formas, que não a realizada sob deliberação consciente. No caso dos seres humanos, fazemos uso de nosso cérebro, para buscarmos compreender o meio que nos cerca. Todas as informações que apreendemos tomam a forma de conhecimento, sendo que de acordo com algumas peculiaridades de cada tipo de experiências que temos, podemos classificar o conhecimento em algumas categorias analíticas, quais sejam:

Conhecimento popular: é aquele resultante das impressões mais imediatistas de nossos sentidos, ou seja, é o conhecimento que não se sabe explicá-lo conforme o padrão científico estabelecido, de causa e efeito. Dizemos que algo é cheiroso apenas por conta do olfato, sem sabermos das minúsculas interações dos neurônios nem das pupilas olfativas. Algo é cheiroso e ponto final. Exemplo: o perfume de uma flor. Tocamos a flor assim como tocamos outras coisas, mas a flor exala uma fragrância agradável ao olfato, e por isso dizemos logo: é cheirosa.

Conhecimento religioso: é quando bus- camos justificar as propriedades de certas coisas em forças sobrenaturais, em que afirmamos que algo acontece sem que seja por motivação humana, mas sim, por um ente desconhecido e abstrato capaz de exercer uma ação sobre algo, de tal forma que se torna uma explicação que pode ser aceita também por outros indivíduos, e neste caso se torna incontestável, com o preceito da autoridade. Assim, o tecido social constituído com crenças comuns de que os mortos possuem outras oportunidades, por meio de seus espíritos, de retornarem à condição anterior à morte, ou seja, à vida, é um conhecimento do aspecto religioso que julgamos proveitoso citá-lo aqui.

Conhecimento filosófico: quando, em vez de explicarmos o mundo sem o uso do senso-comum (sensorial) nem do aspecto religioso, e tentamos argumentações que se direcionam a afirmações abstratas, com jogo de palavras e raciocínio contemplativo, absorto, estamos utilizando o conhecimento filosófico, que é uma forma de explicar as circunstâncias e estruturas a partir de ponto de vista questionador, algumas vezes com extrema meditação, mas que podem levar a conclusões amplas. Tal se dá com a explicação da medida do sol, que algum filósofo disse que teria o mesmo tamanho da sola do pé dele, e, no entanto, sabemos que o mesmo filósofo estava deitado no solo, e conseguira cobrir o espectro solar apenas juntando os dois pés em direção ao sol, daí sua tese de que o sol teria a medida de seus dois pés.

Conhecimento científico: é aquele proveniente da formulação de ideias, com experimentação e comprovação, daí a formulação de uma tese sobre algo. É o caso da modificação do estado líquido da água para o estado sólido, cuja causa é devido à redu- 
ção da temperatura para valores abaixo ou igual à $0 \circ \mathrm{C}$, em que nesta circunstância as moléculas da água terão menor motilidade, estarão praticamente inertes, e aos nossos olhos, no nível macro, assumem a forma de gelo ou água sólida.

Por mais que saibamos, mais sabemos que não sabemos o suficiente, e assim continuamos sempre aprendendo com as pessoas que nos estão próximas. Espera-se que este texto tenha como resultados esta discussão das categorias do conhecimento, pois há momentos em que acontece certa confusão de querermos entender algo que está no conhecimento religioso pelo ponto de vista científico, e assim não dá não. Em outros momentos não queremos saber do bê-á-bá filosófico, e pensamos que as informações do momento é que são as mais importantes, e assim esquecemos que o conhecimento pode ter as suas várias categorias de classificação, e que ao classificarmos, facilitamos o modo como entendemos o mundo.

Toda esta discussão tem como principal contribuição possibilitar a que tenhamos a oportunidade de conhecermos esta pequena porém importante peculiaridade: que o conhecimento humano é imensamente grande, com grandes variações, e que foi possível efetuar uma classificação em tipologias do conhecimento, para possibilitar a organização e estudo do conhecimento. É assim que os pesquisadores têm tido a experiência de debaterem sobre as formas de divisão do conhecimento, porque sempre houve confusão em se comparar os conhecimentos científicos e religiosos, e tentar saber qual seria o mais superior ao outro.

Nota-se que muitas pessoas têm feito relatos em que se podem verificar quais momentos que eles percebem um conheci- mento como pertencente ao senso-comum, ou ao conhecimento filosófico. De fato, o conhecimento científico é o que está mais próximo na maior parte das vezes de quem vivencia o ambiente universitário, mas que no ambiente familiar nós nos dispomos em contato com o senso-comum, e com o conhecimento religioso, e a dificuldade em reconhecer o conhecimento filosófico vem mais da postura de ignorarmos o mesmo, por só considerarmos os outros tipos de conhecimento suficientes para a explicação do mundo.

Por exemplo, há pessoas que afirmam certas informações que não estão adequadamente classificados, mas que o pesquisador mais experiente pode direcionar a discussão de modo a que haja a busca do esclarecimento do que eles estavam pensando, principalmente quando se trata do conhecimento do herbário amazônida, que tanto pode estar elencado no sensocomum, como no conhecimento científico, dependendo de que aspecto está em análise, mas que não podemos enquadrar estritamente no religioso.

\section{OS TIPOS DE PESQUISA}

Conforme Zanella (2009), o processo de pesquisa científica tem por fim apresentar determinadas conclusões, ou os seus indícios, para a sociedade, objetivando proporcionar a solução ou o esclarecimento de determinada situação. Assim, não iremos explicar as formas sistemáticas para se fazer pesquisa, mas dentro de um contexto hermenêutico, apresentaremos uma epistemologia do processo de pesquisa, ou seja, as suas classificações e apresentações.

Deste modo, conforme Zanella (2009), a atividade de pesquisa teve uma divisão em 
torno dos grandes agrupamentos possíveis da pesquisa científica, a qual foi segmentada em duas grandes categorias: a pesquisa pura e a pesquisa aplicada. Apesar desta distribuição fechada, não devemos considera-las como separadas, incomunicáveis, mas são pontos de contatos próximos que propiciam suas ligações, e em alguns momentos seus exclusivismos. Portanto, haverá situações em que estará discernível apenas a pesquisa pura, e em outras a pesquisa aplicada, mas com certeza é possível a ocorrência interligada de ambas.

A pesquisa pura é aquela que é realizada muito dentro do campo teórico, com suas formulações intangíveis, mas que buscam consolidar informações acerca de algo. Por exemplo, o físico brasileiro Marcelo Gleiser (1959-) realiza pesquisas sobre os segundos iniciais da formação do universo. Este tipo de pesquisa é exclusivista teórica, mas que abriu novas informações sobre um campo com poucos dados, que é a física do efeito big-bang. Outro físico, britânico, Stephen Hawking (1942-), estudou os buracos negros do universo, e possibilitou, ele, complementar a teoria dos buracos negros, e afirmar que são geradas partículas subatômicas nos buracos negros, e ampliou a teoria da radiação cósmica.

A pesquisa aplicada é aquela que visa um objetivo mais prático, tal a construção de determinada tecnologia que possa ser desenvolvida e disseminada. Assim, por exemplo, foi utilizada a teoria da transformação da energia em suas diversas modalidades. Alexander Grahan Bell (1847-1922) propôs a utilização de uma película sobre um dispositivo elétrico cônico e criou um tipo de microfone, sendo que este é a transformação da energia sonora em energia elétrica. Esta ideia, cujo fim foi prático, foi um dos pontapés para a da criação do telefone, do rádio e da televisão por outros inventores. O físico brasileiro, César Lattes (1924-2005), conseguiu comprovar a existência da partícula subatômica méson pi por meio de experimentos que envolviam chapas fotográficas, e assim, a ideia das menores unidades da matéria, que antes eram apenas três (próton, elétron e nêutron), passou a ser de subunidades menores ainda, os mésons, que foram inicialmente idealizados pelo ganhador do Nobel de Física, Hideki Yukawa (1907-1981).

Quanto ao método e forma, a pesquisa pode ser classificada ainda em: qualitativa e quantitativa. Na qualitativa, são analisados os dados a partir de suas qualidades, ou seja, não serão notados os aspectos estatístico e matemático do objeto estudo, mas suas disposições idiossincráticas, sendo suas falas analisadas, seus modos, comportamentos, usos de imagens, ilustrações diversas e histórias. Na pesquisa quantitativa o que prevalece são as medições do objeto, para notar como ele se comporta dentro de certo período e sob algumas condições. A pesquisa quantitativa visa apresentar o tratamento estatístico adequado do objeto, enquanto que a pesquisa qualitativa apresentará os pontos de vista dos participantes e do pesquisador. O ideal é o uso de uma ou de outra ou ambas conforme sejam necessárias para aclarar o objeto analisado.

A pesquisa pode ser também exploratória, descritiva ou explicativa. Serão exploratórias quando os dados e informes sobre o objeto selecionado forem muito escassos. Deste modo, a pesquisa exploratória permitirá a captação das primeiras informações sobre algo, como aconteceu, por exemplo, no começo da década de 1980 os primeiros registros de AIDS pelo mundo. Os pesquisa- 
dores só conseguiram apresentar dados seguros apenas seis anos depois - a aprovação do primeiro medicamento a combater o HIV ocorreu em 1987 -, e só obtiveram propostas de tratamento mais de oito anos depois, ou seja, em 1995 com os coquetéis de drogas antirretrovirais para impedir a progressão do HIV (SANTI; VITA; GARATTO$\mathrm{NI}, 2013$ ).

A pesquisa descritiva visa proporcionar informações suficientes sobre algo, de modo a descrever este algo. É o que acontece muito na Amazônia, com os biólogos e naturalistas, que estão sempre descrevendo o herbário amazônida, algumas vezes comparando-o com o de outras regiões, e disseminado tais informações para que mais pessoas tenham acesso a estes conhecimentos tão importantes. Também é o caso de um pesquisador que está fazendo pesquisa descritiva do comportamento das superfícies das folhas das plantas, em torno de suas reações quando expostas à radiação solar e à umidade. Assim, esse pesquisador descreve que as superfícies das folhas apresentam um comportamento de maior rugosidade em certa situação e outro em outra circunstância, mais lisa, e deste modo espera-se utilizar estas informações na confecção dos equipamentos de mergulho e das roupas dos competidores de natação.

A pesquisa explicativa é aquela que objetiva apresentar explicações sobre algo, como nos casos dos psicólogos, que em seus diálogos com adolescentes, buscam compreender os porquês da adoção de certos comportamentos característicos da fase juvenil.

\section{OS PROCEDIMENTOS CIENTÍFICOS}

Quanto aos procedimentos, teremos:
Pesquisa bibliográfica - feita muito sobre fontes bibliográficas apenas, como foi o caso de um pesquisador que descreveu o ambiente das penitenciárias, apenas com os informes dos livros e textos a que teve acesso, sem nunca ter visitado uma cadeia na vida (AMORAS, 2009).

Documental - presente nas situações em que são utilizados documentos de diversas categorias para comprovar-se algo ou relatar uma determinada situação. É o caso dos investigadores que tentam determinar indícios de fraudes bancárias a partir dos registros documentais impressos e eletrônicos de agências bancárias.

Pesquisa por levantamento (surveys) feita quando se quer informações populacionais, e neste caso confunde-se muito com um censo, sendo que este um quer apenas a descrição populacional, enquanto que o levantamento requer algo a mais, tais como as motivações de certas situações, os pontos de vistas dos consultados etc.

Estudo de caso - realizado quando deseja-se conhecer apenas uma situação particular de alguma coisa. Por exemplo, faz-se uso de estudo de caso para saber-se porque uma turma em particular de um curso de graduação apresentou muita dificuldade em relacionar-se bem com certo professor, e a mesma situação não se registrava nas outras turmas. Neste caso, o estudo possibilitou a descoberta de indícios de antipatia de parte da turma com o docente e vice-versa, e tal comportamento foi disseminado com todos os colegas da mesma turma, e gerou muita tensão no grupo estudado.

Pesquisa experimental - está presente quando se quer verificar o comportamento de certo fenômeno por meio de experimentos. É o caso do pesquisador que diz descobrir se o chorume da lixeira pública possuía 
elementos radioativos ou não, e neste caso fez frequentes medições da eletrorresistividade do solo para obter dados que possibilitassem uma conclusão. A mesma técnica da medição de eletrorresistividade está presente nas escavações arqueológicas, quando em vez de fazer enormes buracos no solo, inicialmente verifica-se a presença de elementos enterrados no subsolo apenas pela variação da tensão elétrica do solo (FRAZÃO; MOURA, 2017).

Ex-post-facto - feita quando o fato já houve, que foi o caso da morte do ator Bruce Lee (1940-1973), que após o fato, tentou-se averiguar se foi morte natural ou outros fatores que causaram sua morte. No caso, muito tempo depois, foi possível afirmar que o uso de certo medicamento analgésico causou um edema cerebral no ator de Hong Kong.

O processo de pesquisa científica é realizado com planejamento, e instrumentos e técnicas apropriadas a cada situação, para favorecer o atingimento do objetivo selecionado. Por exemplo, na técnica de pesquisa do experimento, um cientista expõe um grupo de pessoas a certas situações previamente planejadas, objetivando observar algum tipo de comportamento que se quer analisar. Na técnica de aplicação de questionário, o pesquisador pode focar determinadas variáveis que quer analisar, e é útil quando não se tem os dados sobre determinadas características da população, opiniões e comportamentos.

Algumas vezes, acontece de nem o experimento nem o questionário serem as técnicas mais apropriadas para a coleta de dados, e pode-se recorrer à entrevista, sendo que esta é mais útil quando se quer conseguir opiniões, fatos ou testemunhos sobre determinada questão. A estratégia da en- trevista é basicamente esta: o pesquisador elabora um guia de perguntas, seleciona arbitrariamente uma amostra de pessoas, e submete-as à arguição planejada.

No caso de serem efetuadas coletas de dados, ou seja, obtenção de informações necessárias para complementar o trabalho, é necessário planejar o detalhamento dos atos que serão efetuados. Por exemplo, caso preveja-se visita a órgãos públicos, deve-se selecionar quais setores e/ou departamentos e indivíduos serão abordados. Caso realizem-se entrevistas, é bom delinear como dar-se-ão as mesmas, se gravadas por meio de áudio ou se vídeo, se aplicarão formulários de questionários impressos ou por e-mail, se vão tirar fotografias digitais ou filmagens etc. Quanto mais projetaremse a metodologia da pesquisa, melhor é para entender os atos que precisarão ser cumpridos, e assim o planejamento poderá ser facilitado pela visualização do passo-apasso que pretende-se fazer.

\section{CONSIDERAÇÕES FINAIS}

Espera-se que as informações apresentadas neste ensaio tenham ressonância na compreensão do processo de produção científica do conhecimento. $O$ discurso ora apresentado pauta-se muito no debate de como fazer ciência, suas metodologias, sendo que os resultados são as informações que recebemos diariamente pelos meios científicos e também nos produtos do mesmo, sejam obras literárias ou produtos decorrentes da aplicação prática da ciência.

Geralmente, é no ambiente universitário que ocorre o primeiro contato direto com a prática de pesquisa científica. Entretanto, mesmo no Ensino Médio ou no Ensino Fundamental pode haver atos de produção do 
conhecimento, com o suporte metodológico, principalmente quando há acadêmicos realizando as disciplinas de docência, e que porventura intentem aproveitar a oportunidade para a realização esclarecida de experimentos, sejam por meio de mostra de artefatos ou pela coleta de dados. Por isso que o formato de curso de licenciatura ou de bacharelado apresentam suas segmentações que Ihes amoldam suas estruturas curriculares, e o licenciado passa pela experiência de ministrar aula em escolas, conquanto ao bacharel há a introdução do mesmo nos laboratórios e estágios profissionais em empresas.

\section{REFERÊNCIAS}

ALFONSO-GOLDFARB, A. M. O que é História da Ciência. São Paulo: Brasiliense, 2004. AMORAS, F. C. Sistema social da prisão. Jus Navigandi, Teresina, ano 13, n. 2124, abr. 2009. Disponível em: <https://jus.com.br/ar tigos/12701>. Acesso em: 17 mar. 2016.

BRASIL. Constituição (1988). Constituição da República Federativa do Brasil, de 05 de outubro de 1988, atualizada até a emenda constitucional de revisão n. 06 de 07 de junho de 1994 e até a emenda constitucional n. 990 de 15 de setembro de 2015. Disponível em: <http://www.planalto.gov.br/c civil_03/constituicao/constitui\%C3\%A7ao.h tm>. Acesso em: 28 set. 2015.

FAVA-DE-MORAES, F.; FAVA, M. A iniciação científica: muitas vantagens e poucos riscos.

São Paulo em Perspectiva, São Paulo, v. 14, n. 1, mar. 2000.

FRAZÃO, M. V. da C.; MOURA, H. P. Medidas de resistividade elétrica aparente ao redor das ruínas da igreja de pedra de Mazagão-Velho-AP. In: BRITO, A. U.; DALMÁCIO, C. E. da C.; SIMÕES, H. C. G. Q. Ciências
Exatas: resultados dos projetos de iniciação científica da Universidade Federal do Amapá (2012-2016). Macapá: UNIFAP, 2017. p. 83-96.

GOMES, D. da S.; ALVES, M. J. dos S. Tradução, négritude e recepção nos poemas de Léopold Sédar Senghor: abordagem críticoliterária no modernismo. In: BRITO, A. U.; DALMÁCIO, C. E. da C.; SIMÕES, H. C. G. Q. Educação e Linguística: resultados dos projetos de iniciação científica da Universidade Federal do Amapá (2012-2016). Macapá: UNIFAP, 2017. p. 151-164.

SANTI, A. de; VITA, V.; GARATTONI, B. A cura da AIDS. Super Interessante, São Paulo, p. 32-41, ago. 2013.

SOUSA SOBRINHO, M. Extensão universitária: ensino de pesquisa. In: FILOCREÃO, A. S. $M$. et al. (org.s). Juventude da Floresta: relatos de uma experiência. Macapá: UNIFAP, 2017. P. 33-42.

ZANELLA, L. C. H. Metodologia de Estudo e de Pesquisa em Administração. Florianopólis: Departamento de Ciências da Administração/USFC; [Brasília]: CAPES; UAB, 2009.

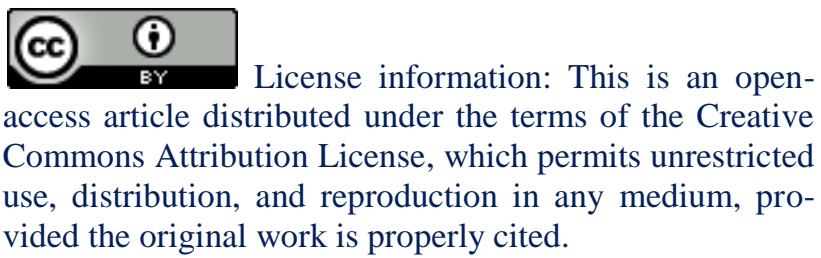

Artigo recebido em 13 de dezembro de 2016.

Avaliado em 26 de dezembro de 2016.

Aceito em 26 de dezembro de 2016.

Publicado em 28 de março de 2017.

\section{Como citar este artigo (ABNT):}

AMORAS, Fernando Castro; AMORAS, Aluana Vilhena. A pesquisa no ensino superior: um ensaio sobre metodologia científica. Estação Científica (UNIFAP), Macapá, v. 6, n. 3, p. 127-136, set./dez. 2016. 